\title{
Are we sitting comfortably? Domestic imaginaries, laptop computing practices, and energy use.
}

Word Count: 8,910 (excluding references)

\section{Abstract}

The considerable literature on domestic consumption practices has tended to focus on either the (re)production and contestation of normative imaginaries, or the links between escalating standards and energy use. Far less has been written which links these related areas together. Accordingly this paper is positioned at the intersection of debates on domestic consumption, energy use and home cultures. Through a qualitative study of laptop use in the home, we illustrate how energy intensive practices such as multi-tasking and alwayson-ness, and changing computer ecologies are intimately bound up with the reproduction of particular domestic imaginaries of family and home. A key insight in this paper is that a purely physiological conception of comfort would fail to fully explain why practices such as multi-tasking and always-on-ness emerge, and thus we theorise comfort as an accomplishment comprised of inseparable temporal, bodily, spatial and material elements. Ultimately we argue here that comfort needs to be understood as a multi-valent imaginary that is itself bound up in broader idealised notions of family and home in order to understand shifting practices, computing ecologies and energy consumption. 


\section{Introduction}

Household energy use accounts for one third of total use (Unander, Ettestøl et al, 2004), and whilst the contribution of information communication technologies (ICTs) to this total is currently relatively low, its future contribution is likely to be anything but (Ropke, 2010). What is increasingly apparent however is that ever-more complex ICT technologies such as laptop computers are now very common in households of the developed world. The most recent figures on UK domestic laptop ownership suggest significant growth, with 30\% of households owning a laptop in 2006 (Shepherd, 2007: 3), rising to 53\% by March 2010 (Rigby, 2010). Such rapid increases also imply subsequent shifts in home computing practices. What is notable by its absence, however, is any sustained research engagement with the household energy implications of this growth in relation to implied shifting domestic ICT practices.

This paper therefore explores this relationship by drawing on empirical materials derived from a recent qualitative study of the role of laptop computers in domestic energy use. The first section of the paper explores salient conceptual frameworks - there is of course a rich vein of work on domestic consumption that has emphasised: the ways in which ICTs both reproduce and contest existing idealised notions of family, home and identity (Attfield, 2000; Church, Weight et al, 2010; Grint and Gill, 1995; Haddon, 1992; Silverstone and Hirsch, 1992; Wacjman, 1991); the affective and sensory dimensions of home consumption (Hadjiyanni \& Helle, 2010; Olesen, 2010; Pink 2004); and the temporal ordering of the home (Pantzar, 2010; 
Southerton, 2006; Tolmie, Pycock et al, 2003; Wacjman, 2008). Practice theory has also generated a timely and apposite body of inter-disciplinary work which links everyday domestic practices and the accomplishment of domestic 'standards' with their underlying energy use (Gran-Hansen, 2010; Hinton, 2010; Ropke, 2009a, 2009b; Shove, 2003, 2006; Shove and Southerton, 2000; Wilhite, Nakagami et al, 2001).

Less attention has, however, been paid to the intersections of these concerns-how shifts in domestic ICT practices, via idealised notions of family and domesticity, might have implications for escalating domestic energy consumption. The paper therefore goes on to analyse changes in domestic ICT practices derived from the empirical study of laptop use. How has the 'work' of domestic ICT consumption (Miller, 1991) in achieving idealised imaginaries of domesticity, entailed shifts in ICT practice comprising aesthetic, embodied, spatial, temporal and social elements? With the introduction of the laptop computer, the domestic ICT ecology has become more spatially mobile, more extensive, and possesses a greater diversity of aesthetic, embodied and place-based elements. Temporally, the use of the laptop as an object in space has become more frequent, more opportunistic and more constant for shorter durations, with a greater diversity of attendant forms of activity and sociality.

The penultimate section interrogates the ways in which these empirical changes in domestic ICT practices have potential consequences for the escalation of domestic direct energy use-particularly with respect to multitasking, wireless infrastructure and constant use. The final section and conclusions discuss some of the environmental implications of increasing 
laptop use within the home, and illustrate some of the ways in which the laptop's role in the achievement of domestic comfort(s) may potentially be increasing the energy used in domestic computing.

\section{Home cultures and ICT consumption practices}

Silverstone, Hirsch et al argued that the project of ICT domestication is essentially one of achieving "home-ness" (1992: 19). Bell and Dourish (2006: 8) similarly argue that an important element in this construction of home is "the nature of domesticity as a social imaginary"-in particular, the ideas and discourses that reproduce (or shift) the normative aspects of everyday domestic life and the social relations that constitute it. The affective dimensions of these imaginaries are particularly important (Miller, 1998), especially the ways in which 'domesticity' symbolically resonates with the ongoing achievement and subjective experience of affects such as 'comfort' in constructing and inhabiting domestic space.

Ingold (2000) developed a 'dwelling perspective' to demonstrate how daily activities and movements in the home are seen to powerfully import and circulate particular configurations of social relations. The social forms that domesticity takes here are seen to arise from socio-technical networks where materiality, practice and spatiality intersect. Pink (2004) has further argued that many of these domestic practices are profoundly sensory, flagging up the importance of the immaterial and affective in producing and contesting domestic imaginaries. Hadjiyanni and Helle (2010) further note the links between everyday domestic activities, the immaterial, and attempts to define 
identity, arguing that domestic imaginaries are produced and sustained through the less tangible aspects of objects, actions and, ultimately, relationships. Furthermore Olesen (2010), in his discussion of domestic 'atmospheres', notes that these are commonly designated as 'ideal' forms of sociality, which in turn feed into idealised notions of family and home.

In terms of domestic ICT practices more specifically, the earliest studies of domestic computing focused on the introduction of the desktop PC into the home environment. A number of dimensions were explored in these studies, from the spatial placement of the desktop PC, through to the values and meanings associated with both the objects and domestic spaces, as well as the familial relationships they facilitate (or not). Lally's mid-90s study of home computing (2002) noted that domestic space is structured and segmented according to particular types of activity. This coding of spaces is one aspect of the 'domestic imaginary' in the achievement of a comfortable home, which turns space into place, and which supports temporal routines (Silverstone, Hirsch et al, 1992: 19). As Lally noted, "the issue of the [desktop] computer's spatial location within the household seems to provide a symbolic indicator of the computer's place within the household-or rather the denial of a place within it" (2002: 193, see also Frohlich and Kraut, 2003; Nie and Erbring, 2002). Indeed, studies of the desktop in the home draw attention to several aspects of the imaginaries and practices of domestic comfort: including the relationship between object aesthetics and the embodied experience of domestic ICT use; the relation of ICTs to the coding of domestic spaces; and the importance of the interaction between ICTs and space that configure the socialities of comfort. Wireless and portable ICTs have therefore 
also present new sets of problems and possibilities with respect to the spaces and times of domestic computing.

A number of studies have indicated that with the increasing ubiquity of wireless in the home, the meanings and practices of ICT use are being revised—with new objects, activities and spaces for them. Gone are the days of the huge and stationary desktop PC. The modern home is now a 'communications hub', and the 'typical' family with children has broadband access, wireless networks, and numerous PCs and mobile devices (Hjorthol and Gripsrud, 2009). At the same time, Jungnickel and Bell (2008: 6-7) look beyond entirely novel imaginings of "go-anywhere" computing to explore how new wireless technologies "find a place" in the home through both activities and spaces. They argue that wireless technology practices remain embedded in existing spaces, routines and behaviours, and that "[t]echnology... is like an introduced species that interrupts, interferes and intervenes with the existing visible and invisible ecology". Fragmented activities and spaces are coexistent: as Wacjman (2008: 66) notes, technologies not only change the meaning and nature of tasks, they also reconfigure "...social relationships between people and the spaces they occupy" (see also Bittman and Wacjman, 2000).

As this indicates, the salient re-spatialisations that the laptop prompts are accompanied by important re-temporalisations. Tolmie, Pycock et al (2003) comment that families are in fact quite fleeting entities in a physical sense, and that it is (temporal) domestic flows and routines that often hold them together, giving set times for interaction. Studies in the domestic use of time have paid some attention to the use of ICTs, but have in many instances 
(c.f. Beauvisage, 2009) reified a particular conceptualisation of time-asduration, and said less about the affective dimensions of temporality. Both Southerton (2006) and Michelson (2005) therefore suggest a shift in focus with respect to time use, looking towards the qualities of time rather than simply its duration (see also Wacjman, 2008). Such strategies potentially draw out the ways in which the introduction of wireless and mobile technologies, and consequent shifting temporal and spatial structures, entails the renegotiation of notions such as togetherness which underpin idealised notions of family (Church, Weight et al, 2010).

Attention towards re-spatialisations and re-temporalisations also implies an investigation of social practices in everyday life. Recent 'practicebased' approaches have extended the investigation of objects and activities in domestic space and time to include the notion that domestic energy use is understood as a (by)product of accomplishments such as comfort and convenience (Shove, 2003; Shove, Watson et al 2007). As Shove (2003) has argued, we need to understand how and why domestic practices change if we are to understand ever-increasing patterns of consumption, energy and resource use. For Shove, research should address how standards of living are established, by "analys[ing] processes underpinning the normalisation of consumption and the escalation of demand" (Shove, 2003: 9). Shove (2006: 294) observes that people do not really consume energy, they consume the services that energy facilitates e.g. showering, television, computing. Accordingly, understanding practice is essential to understanding the consumption of energy and resources, because performing a practice involves a variety of objects, processes and competencies. Indeed, Ropke 
(2010) suggests that it is more apposite to talk of practitioners than consumers, shifting the emphasis from 'having' to 'doing'.

ICTs have certainly received some attention as culturally specific domestic practices that potentially escalate energy use over time (Ropke, 2009a, 2009b, 2010). Gram-Hansen (2010), for example, has explored routine household practices in relation to the standby consumption of appliances. She argues that standby practices are comprised of "sociomaterial configurations" of technology design, user knowledge, daily rhythms and household composition (2010: 159). Such analysis, however, says little about variation amongst these elements in terms of comfort, convenience, or how they relate to ideal notions of familial affect. This is all the more surprising when the empirical evidence discussed suggests that comfort and caring are key factors for some households-who, for example, leave appliances on standby so as not to disturb other family members (2010: 157).

Shove (2003) in particular criticises a sizable literature on practices of household comfort that seeks to define and catalogue particular comfort levels on the basis of physiological (often universalised) conceptions of bodily dis/comfort. She has argued that these approaches position comfort (or its absence) as something measurable (in terms of, for example, air flow and light levels), where any deficiencies can be met through appropriate application of an array of technologies (Hinton, 2010: 18). Physiologicallybased comfort is of course important, and relevant to sustainability because of the intense energy and resource requirements of heating and cooling dwellings in different parts of the world to a particular standard. However, as both Jaffari and Matthews (2009) and Wilhite, Nakagami et al (2001) 
demonstrate, understandings and practices of comfort are culturally defined rather than innate. Not only has much of the literature on domestic practices failed to unpack comfort as a more-than-physiological accomplishment, it has also tended to neglect the relationship between escalating standards of domestic comfort, and attempts to reproduce idealised imaginaries of family, home and the domestic (Munro and Madigan, 1999).

Our departure point, located at the intersection of these debates on domestic consumption, energy use and home cultures, is that it is impossible to fully understand escalating energy use in the home without an appreciation of the interactions between the material and affective elements of domestic assemblages, and the domestic imaginaries which they (re)produce. In order to illustrate this, we analyse qualitative empirical materials that focus on the shift from the use of the desktop to the laptop computer in domestic settings.

The empirical research that informs this paper was carried out in 2009 in the south east of England as part of a larger project on energy use and lifestyles. The strand of research explored here was a study of domestic laptop computers chosen as illustrative of the domestic activities surrounding increasingly resource-hungry, energy-intensive objects and assemblages now found in many western households. A total of twelve participants aged between 21 and 70, all $A B C 1$, were recruited through a large, multi-national laptop manufacturing firm as 'recent purchasers'. The sample was generated so far as possible in consideration of diversity across gender and age categories. The participants were interviewed twice over the course of three months, keeping a diary of laptop use for a period of two weeks between interviews. Participants were initially asked to give a biography of their 
computer use (including their ongoing use of desktops in the home), followed by questions regarding the acquisition and disposal of their laptop computers, as well as upgrading and maintenance, everyday uses, and home energy use. The diary asked participants to record what, where, when and who used the (desktop or) laptop. In addition, ethnographic fieldnotes recorded where computers were located in participants' homes, the software they had on the machines, and details of family members' use of the laptop. These field encounters added additional 'thickness' to the narratives garnered from interview data. Participants' accounts have been anonymised throughout the following analysis in respect of ethical considerations.

The analytic strategy was largely inductive, taking its cue from participants' narratives in the development of analytic themes. It is through such an inductive analytic framework that aesthetics, embodied spaces, temporalities and socialities in the achievement of idealised notions of domestic 'comfort' came to be the focus of the analysis.

\section{Objects, aesthetics and the embodied spaces of comfort}

For many of our participants, important normative and discursive elements in the achievement of 'home-ness' were comfort and relaxation. Far from being straightforward, these were produced both sensorily and symbolically through a variety of subject-object relations, and space-object aesthetics.

The first thing we note is that the coding of ICT objects occurred through an assessment of the object's aesthetic properties, and the consistency of these perceived qualities with the corresponding spaces that 
they inhabited. Lally noted that participants in her study made frequent negative comments in respect of desktop aesthetics, consequently spending a lot of time trying to integrate the aesthetic of the desktop into the home by making covers and furniture to accommodate them — such as efforts to hide computers behind "nice wooden" pieces of furniture (2002: 181). Similarly negative perceptions of the aesthetic qualities of the desktop were ubiquitous in our study, particularly with respect to its size and shape:

“There's no room, I wouldn't want [a desktop] in here, where would I put it? [I]t's... bulky innit. There'd be cables everywhere and at least shoved down there it's out of the way." (Trisha, 18/08/09).

Here Trisha indicates (dismissively) how the untidy and bulky desktop and its cables get shoved out of the way so that their effect on her lounge-room coding is minimised. It is evident here that Trisha does not want the clutter and imposing bulk of the desktop to invade the relaxed atmosphere she wants to achieve in the lounge.

In contrast to the desktop, the size, colour and shape of the laptop generally presents a looser script regarding where the user can reasonably use or store the device-positioning it as non-intrusive-or, if the laptop has the requisite styling, it may be left out to complement other lifestyle objects. The majority of laptops that our participants owned were generally dark coloured plastics following a modern functionalist vein of neutral colours and box-like construction, reflecting efficiency, function and utility-which position them largely as 'work' machines (Lupton and Noble, in Tractinksy, 2005: 29)_ 
in contrast to leisure goods which are much sleeker in shape, texture and colour (Bloch, 1995; Postrel, 2002).

However, the styling of laptops has changed in recent years: as the costs of laptops have fallen, and as their functional specifications have standardised, "appearance and symbolic ownership become more important" (Tractinsky, 2005: 32). This was evident in the case of Phil (15/07/09), who had bought a laptop with a pattern etched into the casing, which he noted was "better than just a black box", and which he positioned alongside other domestically acceptable technology products like his "sleek" Xbox, and LCD TV. Indeed, if the computer's placement is a performed and symbolic indicator of its place within the household, then one of the things that sets the laptop apart from the desktop is its ability to fit into rooms performed and coded for relaxation and comfort-which reproduces rather than challenges normative notions of what comfort ought to entail.

The reproduction of normative notions of 'appropriate' domestic spaces for laptop computing is partly about what the laptop is used for and how it is performed-according to Jane (10/08/09), it is about "being creative", "pleasure", "communication" and the "everyday". This does not, however, explain how the laptop fits into a room by virtue of its ability to be inconspicuous:

“...you get a laptop out and stick it on the table and start using it, but you can put it away. You can't do that with a desktop... With those you had to have somewhere to sit... whereas these you can just sit anywhere..." (Jessica, 17/09/09). 
Jane (10/08/09) adds that at any time, "...I can turn it off, and shove it under a blanket, and say it's not there" , and Dean (18/08/09) remarks that with the laptop, he can "...just tuck it under the sofa to keep it out of the way".

Tolmie, Pycock et al (2003: 199) argue that what makes computing 'visible' or 'invisible' is how visual perceptual qualities are embedded in existing routines. These accounts point to the inconspicuous nature of the laptop because its size and weight allow it to be "tucked" or "shoved" away as if it's "not there" when not in use-and most participants did so. Here, the 'original meaning' of laptop portability (across cities or continents for business) designed into the laptop has been changed. What portability affords the laptop in the domestic context is the ability to be moved from room to room, and to be put away-to be invisible, and unused. Thus, the use that designers originally envisaged for the laptop has been subverted in the domestic context, because what is achieved by users is computing as 'unremarkable' (Tolmie, Pycock et al, 2003)—and it is this that makes it more 'acceptable' than the desktop because it is less disruptive of existing room codings.

There is, however, another even more invisible technology that cannot be ignored, and which has been instrumental in allowing the laptop to move into social domestic spaces: the wireless router, which has opened up possibilities for 'located mobility' (Jungnickel and Bell, 2008) or mobility-inplace. As one participant suggested, "the wireless has got a lot to answer for" in bringing the laptop "into its own" (Damien, 07/07/09). Wireless technology has not only helped to realise domestic laptop portability_it has also helped progress an aesthetic of minimal domestic computing. Whilst there are still 
many cables required for wireless computing, these cables can often be confined to areas where they do not disturb the coding of social spaces. Certainly, the messiness and tidiness of domestic spaces are part of their functional coding by activity-rooms are coded as much by what is in them, as what is in them is coded by the room (Lally, 2002: 207). The 'lack' of paraphernalia and cables which the discrete wireless hub facilitates is part of the laptop's aesthetic, and hence part of what makes the laptop simultaneously acceptable in the 'social' space of the lounge, 'cooking' space of the kitchen, or 'natural' space of the garden.

As implied by judgements on aesthetic qualities, the second important quality of ICTs as objects was in their symbolic association with either work or leisure/pleasure activities. This was apparent in Lally's study where desktop PCs occupied either 'work spaces' (studies) or 'dead spaces' (stairwells), away from spaces of domestic relaxation (2002: 193-195). All participants in our study had similarly negative things to say about the work associations of the desktop PC, which were perceived as incongruent with notions of comfort and relaxation, and which formed barriers to desired feelings of comfort being achieved:

"I think the most important thing... [is] being comfortable using it. I think before... [the desktop] felt more like going to an office, it felt more like work, whereas... [the laptop's] a complementary tool... its... gone from being a piece of equipment to being more something of everyday life like a telephone. [W]hereas before I had it in my head as office work... (I'm doing it because I have to)... now 
I'm downloading the photos because its creative, I'm in communication because I want to be, I'm talking to somebody it's going to give me pleasure, I'm shopping and browsing... it's a more pleasurable thing-it's not a business, it's not an office, it's not a stress thing" (Jane, 10/08/09).

In Jane's account, the laptop contrasts with the desktop, which "wouldn't be allowed" in a domestic social space because it would "infiltrate" the room with its connotations of work. As Jane implies, the coding of objects within a space inform the meanings of that space, and are thus normative, suggesting what a space ought to be used for. Thus, for a room to feel relaxing requires the absence of objects that are coded with work-in Jane's narrative, computing with the laptop is explicitly linked to comfort in opposition to the "work", "business" and "stress" of the desktop. Similarly:

"I don't like computers in the lounge-they're the wrong ambience for a lounge or a dining room... [Y]ou've got to put it somewhere, but in an office... or we're fortunate enough to have space at the top of the stairs... [Y]ou go into the study and see a computer on the desk and you think 'that's fine'. You go into the lounge and you see a computer over there and you think 'eugh!' Well I do anyway. It's just incongruous" (Brian, 05/08/09).

In Brian's account, to have a PC in a social room would be "incongruous", presenting the "wrong ambience"-but he notes its acceptability in study 
'work-space' or stairwell 'non-space'. The lounge (where the majority of laptop use in this study occurred) was largely coded as a social space of relaxation. As Brian commented:

"[The lounge] is a nice room to be in. You don't feel like you're tucked out of the way, it's good lighting, it's a big room, and you just feel very comfortable... I find it very relaxing, whereas up in the study that is your focus, there isn't anything else there, you're up there to do a job, whereas down here you can have a bit more fun... experiment... and all from the comfort of your own lounge" (Brian, 05/08/09).

Along with Jane, Brian notes the importance of the surroundings to associations of comfort-the embodied dimensions of the subjective experience of ICTs in particular spaces. The lounge has "good lighting", it is spacious and a place where you can do "fun" things. Brian also used the laptop in the garden, something echoed by Ray, Jane and Alan. Echoing Brian, Ray (20/07/09) associated the desktop with the home office-full of all its "bits and pieces", "muck", "mess" and "fiddle" — whereas laptop use meant that he could sit in the kitchen or the garden whilst having breakfast and listening to the radio, practices that were congruent with his desire for a relaxing retirement.

A third element in the coding of ICT objects is in the construction of an associated relationship between the computer and the user's body. Many participants drew a boundary between the work associations of the desktop 
and the way the user is oriented to it via desks, chairs and other auxiliary objects (Lally, 2002: 175), and the comfort of laptop use which allows the user to lie down, drink a cup of tea or watch TV. In Alison's account, the laptop's relationship with the body is particularly important:

"I suppose if I've been looking at the desktop all day long it's quite tiring on the old back, whereas if we start the day off... [or] at the end of the day, or a weekend, in the bed, at least you can have a lay down, you know? I've got the telly going, I put my knees up and it just sits there like that..." (Alison, 05/08/09).

Alison's sense of comfort here is gained through how the laptop fits to her body in a way that the desktop never could, something also echoed by others. Phil (17/08/09) pointed to the comfort factor of being able to use the laptop in a certain way on his lap by saying that: “... you can't sit with the desktop on your lap. I suppose you could get a wireless keyboard, but it just doesn't feel as comfortable...". Trisha (18/08/09) noted that: "...getting on the laptop is a different experience really_it's a different shape, its not like sitting at a desk... I can just lie here... watch the telly with it, pop out in the kitchen with it and make a cup of tea". These accounts reinforce Jane's (10/08/09) comments about the way she has changed her bodily orientation to computing, from going to a different room and "being sat in an upright chair', to being "sat in the lounge on the sofa"-with all the affordances of bodily comfort and relaxation that this has.

These narratives all underline the ways in which the size, weight and 
shape of the device are important in bringing the computer to the person, rather than having to bring the person to the computer. The hybrid 'laptop computer-user' that results from this is a much more flexible hybrid than the 'desktop computer-user'. Consequently this new hybrid can now inhabit spaces in ways that were previously impossible, suggesting that a key element of comfort lies in minimising the distance between subject and ICT object, and creating a hybridity lacking in desktop-human interactions (Peters, 2003).

\section{The socialities and temporalities of comfort}

If the domestic spaces of computing are being re-spatialised in the shift from the desktop to the laptop, re-temporalisations are also implied. If users place a desktop in a social space such as the lounge, they have to bear an aesthetic incongruity with respect to the desktop PC as an object. If they locate it in a space where it is 'acceptable', desired flows of domestic life and family relations are interrupted by the absence of the PC user. Thus, when users attempt to hide the desktop away, social relations are disrupted because of the interruption to desired flows of family life when being used. This was illustrated in Ray's narrative:

"[T]he desktop, I was totally tied to sitting at that-and bear in mind I couldn't use it when my wife was there... But as we couldn't be up there at the same time, if she finished working, if I then went up there, then it defeated the object of being in the house together 
because you were never in the same place." (Ray, 20/07/09).

As in other accounts, here the desktop is situated away from social domestic spaces. As a consequence, using it interrupts the flows of everyday life and the maintenance of familial relations which co-presence allows. Whilst Frohlich and Kraut note the potential of the PC to be a sociable device, two thirds of internet use in their study was still conducted alone due to the placement of the desktop (2003: 149).

Comfort thus has a temporal element in that participants took comfort in their social relations with other family members; and if these were disturbed, the general feeling of 'homeness' was reduced. Thus the ability of the laptop to comfortably accommodate existing routines was important to participants. The diaries in particular gave clear indications of temporal shifts in ICT practices according to how the laptop fits computing into existing domestic temporal flows. Joy, for example, used the laptop almost exclusively in the kitchen because the stand-alone PC on the third floor of the house would not allow her to simultaneously be on the computer, as well as watch her children when they were downstairs or outside playing.

According to Joy's account, the laptop allows her to articulate family values of care through parental surveillance-the children can be downstairs on the laptop with her in the kitchen, rather than upstairs. Indeed Joy and the children often used the laptop in the kitchen for activities such as spelling games-as Joy noted "....we do this quite a lot and so they get to practice their spelling and find out where the keys are on the keyboard and learn words from school" (Joy, 11/08/09). This demonstrates both how flexible and 
how social the laptop is in temporal arrangements between parents and children. Joy could cook whilst the children were engaged in their outdoor play or indoor computing, Joy simultaneously performing parental care and education:

"I think the kids use [the laptop] a lot more because I can be making the dinner and they can be sitting here... With the desktop I would have to be sat up there with them... So there's a lot more flexibility on where we use it. It could be in the dining room and they could be in the conservatory. I have been sitting at the dining room table the last couple of days because I can see straight down the garden and see them..." (Joy, 11/08/09).

Whilst one way of viewing Joy's narrative is as reinforcing her stereotypical gendered role in the home as a mother (see Pink, 2004), in Joy's account her use of the laptop is positive because it allows the normal flow of domestic life to continue in a flexible way. As a result, in her interpretation, the laptop has freed Joy from mothering activities associated with particular spaces and times by allowing the children to engage in the activities they want, but in a space of Joy's choosing. This relative freedom is echoed by Kay, a married mother with a five year old daughter:

"Bethan uses [the laptop]... for... programs on the telly that you can go on to all the websites. [A]nd it's much easier if she can go on a laptop, because otherwise I get 'Mum! I'm stuck can you do this?' 
So I have to keep going up and downstairs, so it's much easier if she's just sat down and I'm in here and she just plonks away on it" (Kay, 11/08/09).

Whereas Kay used to have to either sit upstairs with Bethan on the desktop or keep going up and down the stairs, Bethan can now sit wherever Kay is. As a result, in Kay's account she can still watch over Bethan but in a space of her choosing where the normal flow of family routine is less interrupted. As a result, we would suggest that there is an intertwining of the temporal (convenience) and the spatial (comfort), because the dominant social imaginary of domestic comfort is one where an activity that is perceived as comfortable not only takes place somewhere coded as comfortable, but one which also does not interrupt everyday temporal rhythms-rather, it fits comfortably with these routines and flows. Joy and Kay's narratives indicate the laptop's enabling potential, particularly because it allows them to articulate idealised family values of caring, love and being together. Thus, whilst Silverstone, Hirsch et al (1992: 24) note that the domestication of technologies usually articulates gendered roles, in these instances the incorporation of the laptop into family life evidently offers an element of control where time "feels better spent".

Munro and Madigan (1999: 108) have traced how the expectations of family have changed dramatically in the last 40 years, and indeed modern familial ideology emphasizes the importance of 'doing things together'. In our research this translates into togetherness achieved via the use of the laptop. A point to emphasise relating to the flow of domestic life is the laptop's role in 
the maintenance of social relations-facilitating togetherness was noted by virtually all participants:

"[S]itting here being comfortable... you probably spend more time on it down here rather than sat in the office-and usually the missus is sat at the other end of the settee so I show her things and she has a laugh as well. [I]t's literally 'when you've finished with that, can I have it?' So it's more sociable... being sat down here rather than... stuck up there. I don't think Dan really used the computer at all when it was in the office. It's only since we've had the laptop, because it's just easier to use" (Phil, 17/08/09).

Here Phil flags the fact that his wife (Dan) had not previously used the desktop, possibly caught in a gendered role that did not allow her to 'escape' upstairs to the desktop. However Phil now talks about how they both share the laptop on the sofa, to show each other things, and "have a laugh". In contrast to the desktop, which encouraged isolation and being apart, computing with the laptop is more "sociable" and equitable.

That the laptop is swapped and shared on the sofa between partners came across in the diaries of many participants. For example the couples Jane and Ian, and Damien and Emma, generally used the laptop on weekday evenings-usually together in the lounge whilst sitting on the sofa, for leisure. A typical evening would see them using it in 30-60 minute blocks, and then swapping over. This desire for physical closeness was reinforced by Jane, and echoed by Kay: 
"Having it now in the lounge means that it's something that Ewan and I can be doing together whereas before, I saw that I was very isolated if it was in a separate room... [W]hereas now we've got a big comfy sofa that we purposely chose so that we can both stretch out... it's that we can both be doing it together, or we can say 'what are you looking at?'... and so yeah-it's interactive" (Jane, 10/08/09).

"[l]f Roger's home, time together is precious, and I don't like to scoot off upstairs when he's downstairs. So l'll just get the laptop out and he does the same... [I]f we're together then at least you can look up and chat or whatever... And where Bethan is as well, because sometimes we sit down in the lounge together" (Kay, 14/09/09).

As these accounts explicitly state, in busy lives where time together is rare and precious, and where familial togetherness is sometimes fleeting (Tolmie, Pycock et al, 2003), the laptop allows computing to be undertaken whilst maintaining physical proximity during family time. Previous research on desktops suggested that computing meant having to be apart from other family members, leading Livingstone (1992: 121) to suggest that the computer either substituted for, or facilitated, social interaction. As the laptop has reconfigured forms of togetherness in time and space, it now both substitutes for, and facilitates social interaction simultaneously. 
Whilst participants noted that actual interaction may be minimal, they also emphasised the importance of being in each other's presence. As Kay pointed out:

"I think it's really nice to have [a laptop] because in the evening when we're sat together, I might be on the laptop or Richard might be but we're still together and one of us is not holed up in the study for 2 or 3 hours..." (Kay, 11/08/09).

Most accounts suggest a relative uniformity for most families in wanting to be together at certain times of the day (particularly after work in the evenings). The implication in our participants' stories is that computing 'together-alone' is a more comfortable experience because it is not associated with the 'guilt' of being apart from other family members, especially while working, in the same domestic space.

Yet as Livingstone (1992: 128) comments, families differ in their degree of cohesion and dispersal around the house because of their own particular histories, income and house type (amongst other things). In this vein, the findings also indicated that the laptop supports a pragmatic family imaginary by allowing separation of family members. Trisha's diary illustrated that her two teenage sons would often use the laptop elsewhere so that she could watch TV in peace. She noted that when their old desktop sat behind the sofa in the lounge, both boys were fighting over it and playing music they had downloaded. Munro and Madigan (1999: 113) have noted the disruption to notions of family that young adults can cause in the home, and in this 
scenario, the laptop affords the family the space they need to remain on good terms with each other, rather than competing for dissimilar activities in the same times and spaces. In this way, the laptop still allows family relations of love and care to be articulated, but through the separation of antagonistic activities and by giving family members space.

As these accounts suggest, the temporal routines and relations of family life are subtly transformed by the laptop. Indeed the laptop has become popular in these households exactly because it fits into desired and idealised notions of domesticity and family life, rather than disrupting them. The narratives of temporality in our participants accounts centre on the laptop's temporal flexibility: its ability to both accommodate existing routines and to produce new rhythms of activity; to both facilitate the togetherness that characterises domestic comfort (computing 'together-alone') while simultaneously facilitating a harmonious family ideal via separation. As with our other research findings, however, these changing practices do have important implications for domestic energy use.

\section{The environmental implications of changing computing practices}

As we have demonstrated, user desires to maintain (and enhance) comfort are part of a wider project to (re)produce idealised domestic imaginaries of family and home, and it is this that underpins the increasing ubiquity of the laptop computer in the home. There are, however, potential energy implications in this shift to laptop computing (Ropke, 2010). As Shove has outlined in the case of showering (2003) and refrigeration (Shove and 
Southerton, 2000), where changes in practices and infrastructure both make comfort possible, and flow from it, this may come at an environmental cost. In the following section we therefore discuss three potential implications of the growth in laptop computing for home energy use.

\section{Multi-tasking}

Multi-tasking is nothing new within domestic life more generally, nor in the case of computing. Indeed Lally reported that the few users in her study who chose to place their desktop PCs in the lounge often chose to watch television whilst using it (2002: 204). This was reflected numerous times in the present study where the laptop was used to complement television consumption practices:

"[Shopping with the] laptop... its more sociable because in the evening everyone is down here... l'd rather sit here and... halfwatch East-enders whilst I'm doing it..." (Jessica, 17/09/09).

Dean (13/07/09) commented that he used social media more whilst watching the television, because "I've got the laptop near and it's easier just to power it up and if I've got the telly on I tend to have the laptop on as well". Brian $(05 / 08 / 09)$ also noted that if television is "boring" it will be left on in the background with the laptop used for interim interest. In general, television use is anything but passive, with viewers frequently talking over it, ignoring it, walking out of the room or doing something else (Peters, 2003: 80). The use of the laptop is increasingly one of those activities people engage in whilst 
ignoring the TV (or periodically substituting other activities).

Whilst 'ignoring' renders television watching a background activity, the laptop is also used to augment active television consumption:

"In the evenings we'll just flick in between things, so if we're watching the TV... at the same time, then I'll sort of go 'hang on have a look at this', and we'll go click, click and bring it up..." (Jane 06/07/09).

Jane also notes that if they are watching TV and want to seek information about a programme (or it prompts a related thought), then the laptop will be used to complement and enhance the TV—-this makes television-watching increasingly interactive.

Indeed numerous accounts also suggested a changed temporality of computer use where users just 'nip in and out' of computing rather than going to the PC to complete a specific task-again, the laptop is seen to fit in with the flow of life, but also to change the flow of life. In common with televisionwatching, users pick and choose what they want from the laptop, paying attention when it suits them rather than being shackled to it-as Peters notes, "they dip in and out of the media, using it in an active way as part of the fabric of their social activity" (2003: 80). Thus the relationship that users have with the laptop is generally quite different from more purposive desktop use.

What is perhaps most striking in our research is the increasing ubiquity and differing configurations of multiple practices-it is not only televisionwatching that the laptop complements, but a whole range of activities- 
illustrated in the case of Trisha:

"I've had [the laptop] in the kitchen while I was cooking dinner and chatting to Christine down the road on it... and we'll be saying 'have you got your wine in your hand?' while we're tapping away and cooking dinner... So I can just get on and do something instead of just thinking 'I've got to sit there and do this or that, so I'll have to get off in a minute', with [the laptop] it can be wherever I am" (Trisha, 18/08/09).

Trisha talks about the time pressures of practical tasks and the way in which the laptop has meant that she gets more time on the computer. Her diary still shows a large amount of use by her teenage children, but the laptop has not only re-spatialised the way she communicates with her friend, it has also retemporalised it—because she can now do it whilst cooking the dinner.

Whilst the power consumption of desktop PCs has been reduced dramatically in recent years, laptops generally still require less power when in use or on standby: this would seem to be a good reason to promote their use within the home. However as these accounts attest, laptops (unlike desktops) are not used by most participants in isolation from other technologies. As a result, it is possible that the combined energy used in practices of laptop computing (for example, the power consumption of TV + laptop) could actually be higher than that of desktop computing. 


\section{Always-on}

Another side-effect to the laptop's concurrent use with other technologies or activities is that the majority of participants either left the laptop on full power, or on standby/asleep, for much of the day:

"I make sure the TV is always off-not on standby-but the laptop, no. I think it's because I always think I might need to use it, and it might take more energy to keep powering up 3 or 4 times a day than just letting it sleep. I don't know if that's true, but... that's my reasoning... The [desktop] computer upstairs I tend to switch off when I'm done-I'll do what I need to do and then power it down and switch it off completely" (Kay, 14/09/09).

"[It's on] quite a lot I'd say, more than the desktop. I use it on impulse, like if I'm sitting here and I want to... do something, I know that I can just turn it on more or less straight away. [A]nd the internet connection is always on, so it's handy having it asleep..." (Dean, 18/08/09).

"[l leave it on], because l'm a bugger for coming downstairs and thinking 'oh, I just need to check [this]'... so it's easier just to leave it on stand-by and just liven it back up and off you go again. So it's on all the time from 7am when I'm awake all the way through. If I'm not in bed and it's in the study, on my way through I will just hit the on button like l'd turn the kettle on." (Alison, 05/08/09). 
Where the laptop fits into the existing flow of domestic life, participants' accounts suggest that these routine uses do not come pre-formed-rather they are developed in conjunction with the introduction of a new technology into domestic space. Whilst all participants identified a task-specific use of the desktop, the majority of participants described their use of the laptop as much more opportunistic, frequent and often for shorter durations. Dean uses it on impulse, and therefore more (and more frequently) than the desktop. For Kay the laptop should be ready when she wants to use it, and frequently. Alison is more likely to use the laptop on a whim because of its standby start-up speed, and use it in passing 'as if it were a kettle'. Jane also notes that the laptop is left on as she 'flits between' doing other things around the house.

The diary data reinforces these accounts, and demonstrates thatparticularly at weekends-the majority of participants (9 out of 12) left the laptop on all day, only powering it down at night. This frequent and constant use is contrasted in numerous cases to the more focused temporal use of the desktop. As a result, while the laptop is generally more energy efficient than a desktop, it is also left on full-power or asleep for much longer durations (almost constantly). Consequently the energy use of the laptop in any given period may actually be higher than that of the desktop because of the way it is used.

\section{Laptop infrastructure}

In contrast to the uses described above, three participants (Ray, Alan and Joy) used the laptop in a similar way to the more purposive use of the 
desktop. Ray, for example, noted that:

"I turn it off every time I use it, I always shut it down...it's religiously turned off, it's never just put to sleep. I say never but if I was going upstairs for just five minutes then I might [keep it on], but any longer and it would get switched off" (Ray, 02/09/09).

Joy's diary also demonstrated that while the laptop would occasionally be on for an hour with some sleep in between, this was very rare.

Whilst there was some small variation in switching off the laptop however, all participants noted that their wireless router was on 24 hours a day, 7 days a week:

"[The wireless router is] on all the time... We don't turn that off, perhaps we should, but it's slightly more difficult to get to. It sounds terrible doesn't it, but you have to lean over and switch a plug off, but I suppose again it's convenience. If we're downstairs where the laptop is, it's a bit of a faff, 'oh it's not connecting', I've got to go upstairs, turn the router on, come down, it doesn't strike me as being too power-hungry to leave it on, but we should turn it off..." (Brian, 05/08/09).

"[The wireless router is] on all the time, otherwise the phone won't work!... It's the only thing that's on all the time because I do push the buttons on everything, and I'm on pay as you go electric... so I 
do notice if things are left on" (Trisha, 18/08/09).

These accounts point to the way in which the frequent use of the laptop and the 'invisibility' of the wireless router as a supporting technology encourages users to leave the wireless router switched on, and in this study all participants left them on permanently. This included both Joy and Trisha, who were conscious about switching everything else (not just the laptop) off. What also comes across in participants' accounts is the way in which these behaviours are scripted by the technologies themselves. For Brian, it was "a faff" to find the switch for the wireless router because of its awkward position, something also noted by Phil:

"All the power things are tucked behind that unit so I'm not going to keep unplugging it all the time because it's a pain... [A]nd at the end of the day, it's just easier to leave it all on" (Phil, 17/08/09).

Thus for Brian and Phil the router scripts its always-on-ness, because it needs to be positioned near power and phone cables which are invariably hidden. Kay, on the other hand, noted:

"[The wireless router is] on constantly too, the computers might be off, but that's always on. I'm too frightened to switch it off in case it never came back on again" (Kay, 14/09/09).

Here Kay points to the fact that she knows very little about how the router 
operates, and wouldn't know what to do if it didn't restart. Thus, the complexity and uncertainty of the technology (at least in part) scripts her practices. Again, despite the lower power-consumption of the laptop, all participants who owned a wireless router admitted to leaving it on 24-7, even when they went away on holiday.

Rather than concurring with the prevailing 'wisdom' that energy efficient laptops use less energy than power hungry desktops, we argue that when the ways in which laptop use has changed computing practices is considered, it is likely that laptop use (and its role in comfort as a domestic accomplishment) actually requires more energy. Indeed, using the most conservative estimates from a review of PC energy use studies made by Bray (2006), a desktop computer and modem used for two hours per day and then switched off would require half as much energy as a laptop computer used for two hours per day if the wireless router is left on. Thus whilst laptops in themselves generally use less power than desktops, the way they are used implies a net increase in energy resource.

\section{Conclusions}

Wilhite, Nakagami et al (2001: 159) point out that whilst domestic energy use is defined by such factors as dwelling size, appliances, and climate, occupant behaviour remains a central (and under-theorised) element of use. Indeed Shove, Watson et al (2007: 25) argue that the acquisition and use of products (and thus energy use) in the home is bound up with prevailing idealised imaginaries of what constitutes normal or idealised family life. Place remains 
vital in understanding the role of domestic computing: we have shown here that laptop computing not only remains "anchored in place", but it is the desired meanings of the home as a place of comfort which inform the use of the laptop (Jungnickel and Bell, 2008: 9).

We have therefore demonstrated various correspondences between the symbolic meanings of the laptop and the spatial and temporal coding of domestic spaces-ICTs do not just take place, they make place (Brown and O'Hara, 2002). In this study this was achieved through symbolic correspondence (or not) in styling and aesthetics, but also through the attribution of 'work' and 'leisure' meanings to domestic spaces-which contribute to a sense of ease and well-being in users' experiences of 'located mobilities'. The design of the laptop is also crucial, its portability being employed to bring the laptop closer to the body and simultaneously render it unremarkable-and therefore integrate it in areas of the home where computing was previously unacceptable.

We have also highlighted a link between the temporal dimension of comfort and the way that laptop computing allows other domestic routines to remain intact, maintaining interactions and domestic flows which are experienced as comfortable. The acceptance of the laptop in spaces such as the lounge, bedroom and kitchen allows members of the household struggling to maintain a work-life balance to be co-present whilst computing (computing 'together-alone'). Thus the social and embodied nature of domestic comfort is fore-grounded, with the laptop and its attendant infrastructure (notably the wireless router) playing a very significant role in domestic sociality.

Crucially, we have illustrated how multi-tasking, always-on-ness and 
changing computer ecologies are intimately bound up with the reproduction of a particular domestic imaginary of comfort comprised of inseparable temporal, bodily, spatial and material elements. A key insight in this paper is that a purely physiological conception of comfort would fail to fully explain why practices such as multi-tasking and always-on-ness emerge. We argue here that comfort needs to be understood as a multi-valent imaginary, that is itself bound up in broader idealised notions of family and home, in order to understand shifting practices, computing ecologies and energy consumption.

\section{References}

Attfield J., 2000, Wild Things: The material culture of everyday life (Berg, Oxford)

Beauvisage T, 2009, "Computer usage in daily life" CHI-2009: Proceedings of the $27^{\text {th }}$ international conference on human factors in computing systems (ACM, New York) 575-584

Bell G, Dourish P, 2006, "Back to the shed: gendered visions of technology and computing" Personal and Ubiquitous Computing 11(5) 373-381

Bittman M, Wajcman J, 2000, "The Rush Hour: The Character of Leisure Time and Gender Equity" Social Forces 79(1) 165-189

Bloch P, 1995, "Seeking the ideal form: product design and consumer response" Journal of Marketing 59(3) 16-29 
Bray M, 2006, Review of computer energy consumption and potential savings, White paper sponsored by Dragon Systems Software, http://dssw.co.uk/research/computer energy consumption.pdf

Brown B, O'Hara K, 2003, "Place as a practical concern of mobile workers" Environment \& Planning A 35 1565-1587

Church K, Weight J, Berry M, Macdonald H, 2010, "At home with media technology" Home Cultures 7(3) 263-286

Frohlich D, Kraut R, 2003, "The social context of home computing" in Inside the smart home Ed R Harper (Springer-Verlag, London) pp 127-162

Gram-Hansen K, 2010, "Standby consumption in households analysed with a practice theory approach" Journal of Industrial Ecology 14(1) 150-165

Grint K, Gill R, 1995, "The Gender-Technology Relation: Contemporary Theory and Research" in The Gender-Technology Relation: Contemporary Theory and Research Eds K Grint, R Gill (Taylor and Francis, London) pp 128

Haddon L, 1992, "Explaining ICT consumption: the case of the home computer" in Consuming technologies: media and information in domestic spaces Eds R Silverstone, E Hirsch, (Routledge, London) pp 82-96

Hadjiyanni T, Helle K, 2010, “(Im)materiality and practice: craft-making as a 
medium for reconstructing Ojibwe identity in domestic spaces" Home Cultures 7(1) $57-84$

Hinton E, 2010, Review of the literature relating to comfort practices and socio-technical systems Working Paper 35, Environment, Politics and Development Working Paper Series, Department of Geography, King's College, London http://www.kcl.ac.uk/content/1/c6/03/95/42/HintonWP301.pdf

Hjorthol R, Gripsrud M, 2009, "Home as a communication hub: the domestic use of ICT" Journal of Transport Geography 17 115-123

Ingold T, 2000, The perception of the environment: essays on livelihood, dwelling and skill (Routledge, London)

Jaffari S, Matthews B, 2009, "From occupying to inhabiting: a change in conceptualising comfort" in Beyond Kyoto: addressing the challenges of climate change. IOP Conference Series: Earth and Environmental Science 8 012008 (IOP Publishing, Aarhus) pp 1-14

Jungnickel K, Bell G, 2008, "Home is where the hub is? Wireless infrastructures and the nature of domestic culture in Australia" in Handbook of Research on Urban Informatics: Community Integration \& Implementation Ed M Foth (IGI Global, Hershey, PA)

Lally E, 2002, At home with computers (Berg, Oxford)

Livingstone S, 1992, "The meaning of domestic technologies: a personal construct analysis of familial gender relations" in Consuming technologies: media and information in domestic spaces Eds R Silverstone, E Hirsch, 
(Routledge, London) pp. 113-130

Michelson W, 2005, Time use: expanding the explanatory power of the social sciences (London, Paradigm)

Miller D, 1991, Material Culture and Mass Consumption (Oxford, Blackwell)

Miller D, 1998, A Theory of Shopping (Polity Press, Cambridge)

Munro M, Madigan R, 1999, "Negotiating space in the family home" in An Anthropology of Domestic Space Ed I Cieraad (Syracuse University Press, Syracuse)

Nie NH, Erbring L, 2002 "Internet and Society: a preliminary report" IT \& Society 1(1) 275-283

Olesen, BB, 2010, "Ethnic objects in domestic interiors: space, atmosphere and the making of home" Home Cultures 7(1) 25-42

Pantzar M, 2010, "Future shock - discussing the changing temporal architecture of daily life" Journal of Future Studies 14(4) 1-22

Partridge C, 2005, Social change, time use and ICTs - a literature review $\begin{array}{lll}\text { Chimera } \quad \text { Porking 2005-05, } & \text { Naper No. }\end{array}$ http//www.essex.ac.uk/chimera/projects/esoctu/ 
Peters S, 2003, "Emotional context and 'significancies' of media" in Inside the smart home Ed R Harper (Spinger-Verlag, London) 79-97

Pink S, 2004, Home Truths (Berg, Oxford)

Postrel V, 2002, The Substance of Style (Harper Collins, London)

Rigby C, 2010, "More than 50\% of UK adults now shop online" Internet Retailing 27 April, http://www.internetretailing.net/2010/04/more-than-50-ofuk-adults-now-shop-online/

Ropke I, 2009a, "Integration of ICT in everyday life - exploration of transition processes in an environmental perspective" Paper presented at the 8th International Conference of the European Society for Ecological Economics, Ljubljana, Slovenia, $29 \quad$ June $\quad$ - 2 July 2009 http://www.esee2009.si/papers/Ropke\%20-\%20Integration\%20of\%20ICT.pdf

Ropke I, 2009b, "Theories of practice - new inspiration for ecological economic studies on consumption" Ecological Economics 68 2490-2497

Ropke I, 2010, "Managing (un)sustainable transitions - bringing the broadband society on the right track?" Paper presented at the 11th Biennial Conference of the International Society for Ecological Economics, Oldenburg and Bremen, 22 - 25 August 2010. Advancing Sustainability in a Time of Crisis

http://www.man.dtu.dk/English/About/personer.aspx?lg=showcommon\&id=26 $\underline{6982}$

Shepherd A, 2007, "Use of ICT amongst Households and Individuals" in Focus on the Digital Age Eds V Avery, E Chamberlain, C Summerfield, L Zealey (Office for National Statistics, Palgrave Macmillan, Basingstoke) 1-6 
Shove E, 2003, Comfort, Cleanliness and Convenience (Berg, Oxford)

Shove E, 2006, "Efficiency and consumption; technology and practice" in The Earthscan reader in sustainable consumption Ed T Jackson (Earthscan, London) pp 293-305

Shove E, Southerton D, 2000, "Defrosting the freezer: from novelty to convenience" Journal of Material Culture 5 301-319

Shove E, Watson M, Hand M, Ingram J, 2007, The Design of Everyday Life (Berg, Oxford)

Silverstone R, Hirsch E, 1992, "Introduction" in Consuming technologies: media and information in domestic spaces Eds R Silverstone, E Hirsch (Routledge, London) pp 1-11

Silverstone R, Hirsch E, Morley D, 1992, "Information and communication technologies and the moral economy of the household" in Consuming technologies: media and information in domestic spaces Eds R Silverstone, E Hirsch (Routledge, London) 15-31

Southerton D, 2006, "Analysing the Temporal Organization of Daily Life: Social Constraints, Practices and their Allocation" Sociology 40(3) 435-454

Tolmie P, Pycock J, Diggins T, Maclean A, Karsenty A, 2003, "Towards the unremarkable computer: making technology at home in domestic routine" in Inside the smart home Ed R Harper (Spinger-Verlag, London) pp 183-206. 
Towers I, Duxbury L, Higgins C, Thomas J, 2006, "Time thieves and space invaders: technology, work and the organisation" Journal of Organisational Change Management 9(5) 593-618

Tractinsky N, 2005, "Does aesthetics matter in human-computer interaction?" Mensch \& Computer 2005: Kunst und Wissenschaft - Grenzüberschreitungen der interaktiven Ed C Stary (München: Oldenbourg Verlag) http://mc.Informatik.Unihamburg.De/konferenzbaende/mc2005/konferenzband/muc2005 02 tractinsk y.pdf pp 29-42

Unander F, Ettestøl I, Ting M, Schipper L, 2004 "Residential energy use: An international perspective on long-term trends in Denmark Norway, and Sweden" Energy Policy 32(12) 1395-1404

Wacjman J, 1991, Feminism confronts technology (Allen and Unwin, Sydney)

Wacjman J, 2008, "Life in the fast lane? Towards a sociology of technology and time" The British Journal of Sociology 59(1) 59-77

Wilhite H, Nakagami H, Masuda H, Yamaga $Y$ and Haneda H, 2001, "A crosscultural analysis of household energy-use behaviour in Japan and Norway" in Consumption: Critical Concepts in the Social Sciences, Ed D. Miller 4 (Routledge, London) pp. 159-177 